The Israeli Journal of Aquaculture - Bamidgeh, IJA_72.2020.1120903., 11 pages

CCBY-NC-ND-4.0 • https://doi.org/10.46989/001c.21469

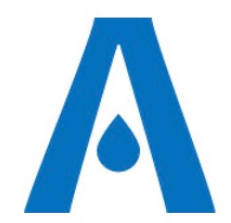

The $I J A$ is a peer-reviewed open-access, electronic journal, freely available without charge to users

Produced by the AquacultureHub non-profit Foundation Sale of IJA papers is strictly forbidden

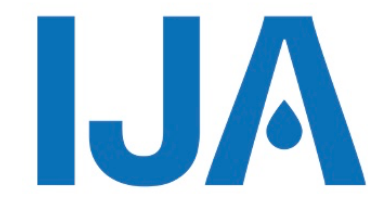

\title{
Population Genetic Analysis of Rainbow Clam Moerella iridescens by Using rDNA
}

\author{
Xiaoying $\mathrm{Li}^{1,2}$, Min Zhang ${ }^{1}$, Guanzheng $\mathrm{Lu}^{1}$, Shuang Mao ${ }^{1}$, Ruixue \\ $\mathrm{Wu}^{1}$, Hongxing $\mathrm{Ge}^{1,2}$, Xueping Meng ${ }^{1}$, Zhiguo Dong ${ }^{1,2 *}$
}

1 Jiangsu Key Laboratory of Marine Bioresources and Environment, Jiangsu Ocean University, Jiangsu, Lianyungang 222005, China

${ }^{2}$ Co-Innovation Center of Jiangsu Marine Bio-industry Technology, Jiangsu Ocean University, Jiangsu, Lianyungang 222005, China

Key words: Moerella iridescens; rDNA; genetic differentiation; ITS

\begin{abstract}
To assess the genetic background of the germplasm resource of rainbow clam Moerella iridescens along China coasts, population genetic structure and genetic diversity of rainbow clam from five geographical populations in the Yellow Sea and the East China Sea (Lianyungang, Chongming, Cixi, Zhoushan, and Ningde) were analyzed based on rDNA (ITS1-5.8S-ITS2) sequences. Forty-Seven rDNA haplotypes were identified among 109 rainbow clam individuals of the five populations. Gen 4 and Gen21 were the dominant haplotypes, accounting for $49.5 \%$ of rDNA whole gene sequences, and shared by the five populations. Six to eight exclusive haplotypes were found in each population. The average haplotype diversity index (HD) of the five populations was 0.8733 . The genetic distance among populations ranged from 0.002 to 0.004 , and haplotypes from the same population were not clustered in a single clade. Molecular variance analysis (AMOVA) demonstrated that the main genetic differentiation mainly occurred within population, and the genetic differentiation coefficient (FST) among five populations was between -0.02836 and 0.01896 , which meant that no genetic differentiation among populations occurred. Overall, the five geographical populations showed a high genetic diversity, but no evident genetic structure or genetic differentiation.
\end{abstract}

\footnotetext{
* Corresponding author. e-mail: dzg7712@163.com; Xiaoying Li and Min Zhang
} contributed equally 


\section{Introduction}

The rainbow clam Moerella iridescens, which is commonly known as "sea melon seeds" in China, is one of the most high-valued mudflat cultured shellfish in the west coast of the Pacific Ocean. It is widely distributed in the southeastern coast in China with the largest natural resources in Zhejiang and Fujian, but also distributed along the coast of the Qinhuangdao (Hebei), Yellow River Delta (Shandong), Lianyungang (Jiangsu), Chongming Island (Shanghai), and Haimen (Guangdong), and etc. The different climate of each sea area and the diversity of ecological environment may lead to genetic differentiation among the geographical populations of $M$. iridescens, which is closely related to its adaptability, reproductive capacity and evolutionary potential (Sokal et al., 1989). For the recent more than a decade, over-exploitation and shrimp farming in the inning beach have led to a fragmented natural ecological environment of $M$. iridescens in habitat, degradation of germplasm resources, and severely declining resources quantity of $M$. iridescens (Li et al., 2009; You and Wang, 1990a, 1991b). So it is necessary to effectively assess genetic resources so as to take rational conservation strategies. The richer the genetic diversity of a species, the stronger its adaptability to environmental changes, and it is easy to expand its distribution range (Su et al., 2007). Therefore, assessing population genetic diversity is of great scientific and practical significance in protecting and managing the germplasm resources of $M$. iridescens.

A few of reports are available regarding the germplasm resources and molecular biology of $M$. iridescens. In the analysis of geographical population morphological variation and micro chemical composition in the population, the heavy metal pollution characteristics of M. iridescens in Hangzhou Bay and Haizhou Bay were quite different, which also indicated that the habitat of $M$. iridescens was greatly affected by human beings ( $L i$ et al., 2010a; Dong et al., 2012). ISSR primers for germplasm evaluation of $M$. iridescens was established, the genetic differentiation analysis of three populations in Hangzhou Bay and Haizhou Bay was carried out using ISSR primers (Dong et al., 2010). 32 ideal microsatellite markers were obtained by using magnetic beads enrichment method. The results showed that there was a high genetic diversity and differentiation between the northern and southern populations of $M$. iridescens, which provided a scientific basis for germplasm protection and breeding of $M$. iridescens ( $\mathrm{Li}$ et al., 2010b, 2013). RAPD technology was used to analyze the genetic diversity of $M$. iridescens in Wenling, Zhejiang Province, indicating there were high genetic diversity and differentiation between the northern and southern populations (Yu et al., 2006). Hwang (2015) comparatively analyzed the phylogenetic relationship of five species of shellfish belonging to Tellinidae, including $M$. iridescens, by using mtDNA, a protein-encoding gene (PCG). The result of mitochondrial DNA analysis provided information for study on phylogenetics; however, more proofs on the genetic structure and population genetic relationship of the germplasm resources of $M$. iridescens are still required.

The ribosomal DNA (rDNA) gene coding region successively encodes $18 \mathrm{~S}, 5.8 \mathrm{~S}$, and $28 \mathrm{~S}$ rRNA, which are separated by ITS1 and ITS2. ITS Internal transcribed spacer, which exists variations in nucleotide substitution, deletion, and insertion, is a convenient molecular genetic marker for phylogenetic and species identification analysis at eukaryotic organism in population and species levels (Si et al., 2016; Alexander et al., 2017).

Many studies have reported on ITS sequences about bivalve phylogeny (Wood et al., 2007; Salvia et al., 2012; Hurtado et al., 2011; Guo et al., 2019), species identification (Juan et al., 2010; Yu et al., 2005a, 2006; Pan et al., 2006), and population genetics (Cheng et al., 2006; Lin et al., 2009; Tran et al., 2015; Yuan et al., 2008; Zhou et al., 2012). However, rDNA analysis of the genetic diversity of $M$. iridescens has not been conducted. Thus, this study aims to analyze the genetic diversity, genetic structure, and the genetic differentiation of five geographically different populations of $M$. iridescens in China by analyzing rDNA ITS sequence. These results will provide scientific reference information for germplasm research of $M$. iridescens. 
Experimental Sample Collection.

\section{Materials and Methods}

M. iridescens samples were collected from the natural sea areas of the Yellow Sea and the East China Sea, including Jiangsu Lianyungang (LYG), Shanghai Chongming (CM), Zhejiang Cixi (CX), Zhejiang Zhoushan (ZS) and Fujian Ningde (ND) (Figure 1). The uninjured living specimens were selected and brought back to the laboratory. The surface attachments of the samples were removed and samples were temporarily raised in sterilized seawater (salinity: 15 , temperature: $20^{\circ} \mathrm{C}, \mathrm{pH}: 8.2$ ) and aerated until DNA extraction.

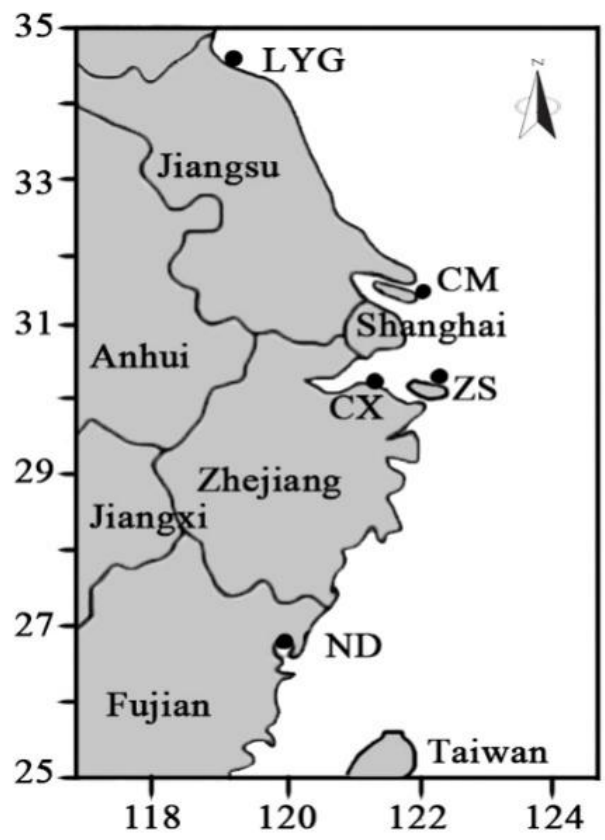

Figure 1 Sampled locations of M. iridescens along China coast. Locations of the 5 studied geographical populations along China coast and the sample sites indicated by the circle dot. LYG: Lianyungang, CM: Chongming, CX: Cixi, ZS: Zhoushan, ND: Ningde

\section{DNA Extraction.}

Before sampled, rainbow clams were anesthetized on ice for $30 \mathrm{~min}$, and then dissected. The mantle muscle tissue, which was approximately $20-30 \mathrm{mg}$ of each individual, was extracted, dried, placed in a labeled $1.5 \mathrm{~mL}$ centrifuge tube, and cut into pieces with scissors. The animal experiments were conducted in accordance with the guidelines and approval of the ethics committees of Jiangsu Ocean University. Total DNA was extracted using phenol-chloroform. The extracted DNA was detected by $1 \%$ agarose gel electrophoresis.

\section{Primer Design and PCR Amplification.}

The rDNA sequence of $M$. iridescens was retrieved and downloaded from GenBank. PCR primers were designed with Primer Premier 5.0. The upstream primer Mir18 is $5^{\prime}-$ GGTGAACCTGCGGATGGA-3' (In 18SrDNA region), and the downstream primer Mir28 is $5^{\prime}-$ GGCTCTTCCCGCTTCACTC-3' (In 28SrDNA region).

Each $20 \mu \mathrm{L}$ of the PCR reaction mixture was composed of $2.0 \mu \mathrm{L}$ of DNA template, $10.0 \mu \mathrm{L}$ of $2 \times$ Taq PCR Mix containing Taq DNA polymerase, dNTPs, $\mathrm{MgCl}_{2}$, and Tris buffer, $1.0 \mu \mathrm{L}$ of Mir18 and Mir28 primers, and $6.0 \mu \mathrm{L}$ of $\mathrm{ddH}_{2} \mathrm{O}$.

The PCR reactions consisted of initial denaturation at $94^{\circ} \mathrm{C}$ for $5 \mathrm{~min}$, followed by 20 cycles of denaturation at $94^{\circ} \mathrm{C}$ for $45 \mathrm{~s}$, annealing at $62^{\circ} \mathrm{C}$ for $45 \mathrm{~s}$, extension at $72{ }^{\circ} \mathrm{C}$ for $55 \mathrm{~s}$, and 20 additional cycles with ideal conditions except that the annealing temperature was changed to $60^{\circ} \mathrm{C}$. Finally, the reaction was extended at $72{ }^{\circ} \mathrm{C}$ for $8 \mathrm{~min}$. 
PCR Detection and Sequencing.

The PCR products were separated by $1 \%$ agarose gel electrophoresis and visualized using a gel imaging system. The PCR amplification products were purified and recovered by Shanghai Bioengineering Co., Ltd., China. Forward DNA was sequenced by the ABI377 automatic sequencer.

\section{Statistical Analysis.}

The measured sequences were checked and compared with Seqman software, and checked manually, then Clustal X1.83 software was then used to perform sequence multiple alignments. Haplotype, gene diversity, and nucleotide diversity were calculated to estimate DNA polymorphism DnaSP5.1. The genetic structure and genetic differentiation index (FST) among populations were performed using Arlequin3.1 software (Excoffier et al., 2005), and Tajima's D neutral test (Tajima et al., 1989) and AMOVA were carried out. Sequence characteristics were analyzed by MEGA 4.0 software, and the number of various sites and genetic distances within and between populations were counted. The phylogenetic tree was constructed by UPMGA cluster methods based on Kimura 2-parameter corrected distance.

rDNA Sequence Characteristics.

\section{Results}

rDNA sequences of 205 specimens from five separate populations were amplified and sequenced. After comparison and correction, 109 rDNA fragments with a length of 679$686 \mathrm{bp}$ were obtained for analysis, including partial ITS1 sequences, partial ITS2 sequences, and complete 5.8S rRNA sequences. Sequence alignment results displayed 694 specific sites, 76 variable sites (comprise $9.51 \%$ ) and 18 reduced sites (comprise $2.59 \%$ ). The average contents of base T, C, A, and G were $18.7 \%, 33.3 \%, 16.0 \%$, and $32.0 \%$, respectively.

Population Haplotype Distribution and Genetic Diversity.

Forty-seven haplotypes, which accounted for $43.1 \%$ of the total sequences, were detected in the 109 rDNA fragments of the five populations. Two haplotypes were shared among the five populations; eight haplotypes were shared between two populations (Table 1). The 37 exclusive haplotypes detected among the five populations included eight haplotypes in LYG (Gen 1, 11, 16, 20, 23, 26, 28, and 43), six haplotypes in ZS (Gen 2, 7, 17, 24, 32, and 42), eight haplotypes in CX (Gen 6, 14, 18, 25, 33, 35, 37, and 38), seven haplotypes in ND (Gen 3, 5, 9, 22, 31, 41, and 46), and eight haplotypes in CM (Gen 10, 12, 32, 42, $19,30,34,40,45$, and 47 ). The average number of haplotypes diversity was 0.8733 , with a range of $0.8297-0.9368$.

Table 1 Shared rDNA genotypes among five M. irridescens populations

\begin{tabular}{ccccccc}
\hline Genotype & LYG no. & ZS no. & CX no. & ND no. & CM no. & subtotal \\
\hline Gen 4 & 3 & 5 & 5 & 5 & 2 & 20 \\
Gen 21 & 9 & 9 & 6 & 3 & 7 & 34 \\
Gen 8 & - & 1 & 1 & - & - & 2 \\
Gen 13 & 1 & - & - & - & 1 & 2 \\
Gen 15 & - & - & - & 1 & 1 & 2 \\
Gen 27 & 1 & - & - & - & 1 & 2 \\
Gen 29 & - & 1 & - & 3 & - & 4 \\
Gen 36 & - & - & - & 1 & 1 & 2 \\
Gen 39 & - & 1 & - & - & 1 & 2 \\
Gen 44 & - & - & 1 & 1 & - & 2 \\
Total & 14 & 17 & 13 & 14 & 14 & 72 \\
\hline
\end{tabular}


The nucleotide diversity among the five populations ranged from 0.0090 to 0.0135 , and Tajima's D value of the ITS sequences of the five populations was between -1.2456 and 1.6473 (Table 2), implying the lack of a strong, balanced selection in the past and the relatively stable equilibrium of the population size.

Table 2 rDNA genotype information in $5 \mathrm{M}$. irridescens populations

\begin{tabular}{ccccccc}
\hline Stock & SN. & GN. & PG & GD & ND & Tajima's $D$ \\
\hline LYG & 22 & 12 & 8 & $0.8312 \pm 0.0760$ & $0.008985 \pm 0.04952$ & -1.59607 \\
ZS & 24 & 11 & 8 & $0.8297 \pm 0.0627$ & $0.009245 \pm 0.05062$ & -1.64715 \\
CM & 22 & 15 & 6 & $0.9048 \pm 0.0567$ & $0.013545 \pm 0.007216$ & -1.41329 \\
CX & 21 & 12 & 8 & $0.8810 \pm 0.0530$ & $0.01286 \pm 0.006896$ & -1.64728 \\
ND & 20 & 13 & 7 & $0.9368 \pm 0.0354$ & $0.013269 \pm 0.007118$ & -1.24557 \\
\hline
\end{tabular}

Population Genetic Structure and Genetic Differentiation.

AMOVA results of the five populations are shown in Table 3, which showed that the genetic differences mainly occurred within the population, accounting for $101.09 \%$ of variation. As shown in upper right corner of Table 4, the value of $F_{S T}$ ranged from -0.028 to 0.019 , with an average of -0.0108 , indicating the lack of genetic differentiation in population level. The genetic distance and genetic differentiation between the five populations of rainbow clam based on rDNA were shown in Table 4, the genetic distance among populations ranged from 0.002 to 0.004 . The genetic distance between CX and ND was the highest (0.004), and the genetic distance of LYG-SH and LYG-ZS was the lowest (0.002). Overall, the genetic distances among populations were very small, so these five populations can be recognized as whole population in genetic resources.

Table 3 Analysis of molecular variance (AMOVA) across M. irridescens populations

\begin{tabular}{ccccc}
\hline Source of variation & Df & Sum of squares & Variance component & Percentage of variation \\
\hline Among populations & 4 & 12.122 & $-0.04261 \mathrm{Va}$ & -1.09 \\
Within populations & 104 & 411.676 & $3.95843 \mathrm{Vb}$ & 101.09 \\
Total & 108 & 423.798 & 3.91582 & 100 \\
\hline
\end{tabular}

Table 4 Pairwise $F_{S T}$ and pairwise distance of $M$. irridescens population (rDNA)

\begin{tabular}{cccccc}
\hline & CX & LYG & ND & CM & ZS \\
\hline CX & 0.004 & -0.02243 & -0.01103 & -0.02571 & -0.01784 \\
LYG & 0.003 & 0.002 & 0.01086 & -0.00832 & -0.02832 \\
ND & 0.004 & 0.003 & 0.003 & -0.02618 & 0.01896 \\
SH & 0.003 & 0.002 & 0.003 & 0.003 & 0.00084 \\
ZS & 0.003 & 0.002 & 0.003 & 0.003 & 0.003 \\
\hline
\end{tabular}

Lower left corner of the table: genetic distance; upper right corner: genetic differentiation index $\left(F_{S T}\right)$; Diagonal italics are genetic distances within populations; Corresponding number of the same population is the genetic distance within the population. 
Phylogenetic Relationship Analysis.

Based on the rDNA haplotype, MEGA7.0 software was used for the cluster analysis of the five populations (Figure 2). Although some clades with a support rate of $>50 \%$ were found, they were clustered from the specimens of different populations. The haplotypes in a population were not completely clustered together. In general, no evident from genetic structure and differentiation among populations were found.

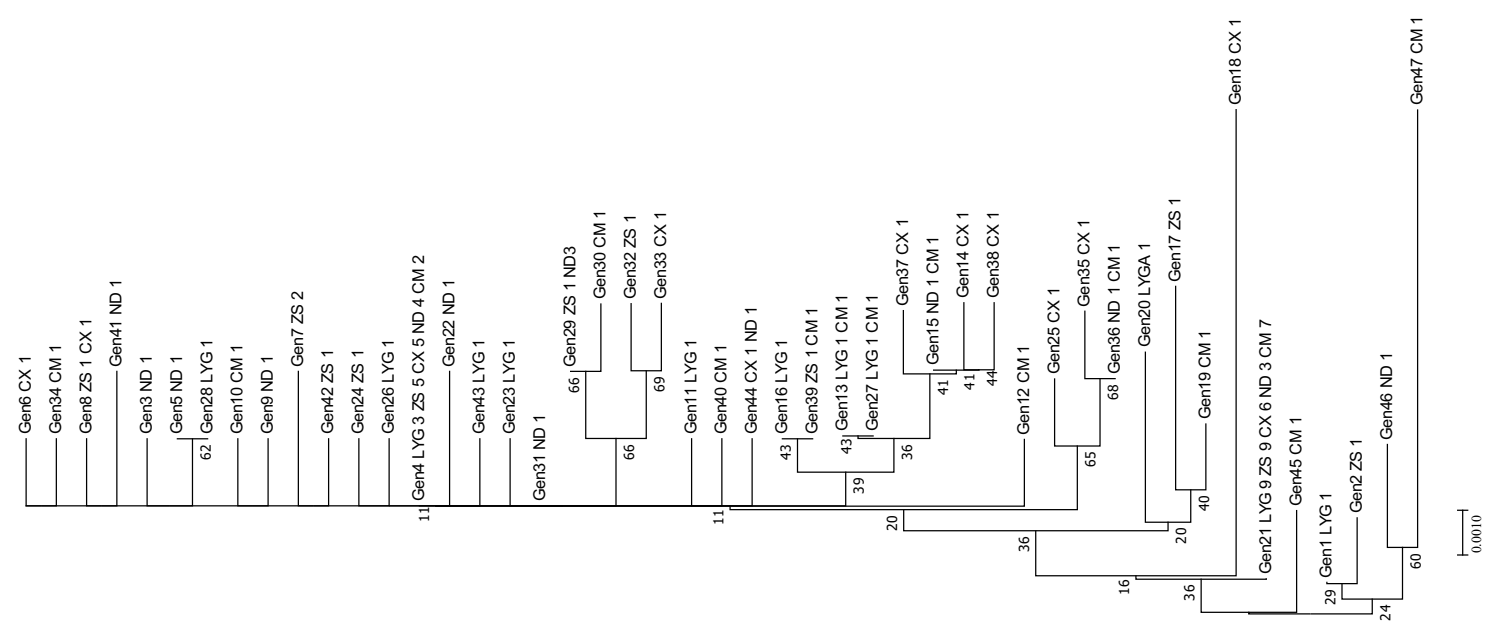

Figure 2 Genetic relationships among the five populations of $M$. irridescens based on the rDNA genotypes

\section{Discussion}

rDNA as a molecular marker is appropriate in exploration of genetic variation for mollusk species and population level. The total rDNA sequence used in this study was 679-686 bp, composing $5.8 \mathrm{~S}$ rDNA total sequence (157 bp), ITS1 partial sequences (331-335 bp) and ITS2 partial sequences (191-194 bp). The search with the Blastn program in the NCBI database indicated 100 related species based on rDNA sequences, including 19 species of Bivalvia belonging to four orders, namely, Veneroida, Arcoida, Myoida, and Mytiloida. The sequence alignment revealed that the total nucleic acid mutation rate of the four orders was $6.45 \%(10 / 155)$. Among these, $5.8 \mathrm{~S}$ rDNA sequences (81) of five species belonging to Perna showed no mutation. The 5.8S rDNA nucleotide mutation rate was $1.29 \%$ among the five species of Perna, namely, $P$. perna, $P$. viridis, $P$. canaliculus, $P$. picta, and $P$. idica, and three species of Mytilus, namely, M. edulis, M. galloprovincialis, and $M$. trossulus. This finding indicated that ITS1 and ITS2 were the main sources of nucleotide mutation in the genetic variation analysis of $M$. iridescens based on rDNA sequence.

The genetic distances among populations of $M$. iridescens computationally based on rDNA sequence were between 0.002 and 0.004 , which was within the intraspecific genetic distance (Freeland, 2005). Thus, a low leveled intraspecific difference was found among different populations of $M$. iridescens. The genetic distance reflects the proximity relationships inter- and intraspecies (Peng et al., 2012). The results of this study and previous studies indicate that the intraspecific genetic distance of the ITS1 and ITS2 sequences ranged from 0.000 to 0.010 , the maximum was approximately $1 \%$, and the interspecific genetic distance was generally over $1.5 \%$. For example, variation analysis of the ITS1 sequence on different geographical stocks of Coelomactra antiquata showed that the genetic distances of the four undifferentiated populations were between 0.00739 and 0.01030 . Meanwhile, the genetic distances between the differentiated Changle population and the four other populations ranged from 0.03171 to 0.03380 (Meng et al., 2010). Regarding ITS1, the genetic distances of four species, namely, E. coioiaes, E. awoara, E. tauvina, and $E$. sexfasciatus belonging to Epinephelus, were between 0 and 0.0972 ; the genetic distances of the former three ranged from 0 to 0.0085 (<0.01) (Zhou et al., 2015). 
Moreover, the genetic distances of the eight species of Thunnus were between 0.0032 and 0.0810 (Qiu et al., 2010). The genetic distances of the four geographical populations of Scapharca broughtonii (Huangdao, Penglai and Qiansandao in China, and Tongying in Korea) ranged from 0.0026 to 0.0064 (ITS1) and from 0.0043 to 0.0137 (ITS2) $(<0.015)$ (Zhou et al., 2012). Chinese Pinctada fucata, Japanese $P$. fucata martensii, and Australian $P$. imbricata had genetic distances of $0.0054-0.0087$ (ITS1) and $0.0077-0.0120$ (ITS2) within populations as well as $0.0067-0.0090$ (ITS1) and 0.0087-0.0125 (ITS2) among populations (Yu et al., 2006). The three species of Pinctada martensii belong to the same species. The intraspecific and interspecific genetic distances of the six species of Pinctada based on ITS2 were between 0.004 to 0.014 and 0.088 to 0.318 (Yu et al., 2005b). The intraspecies genetic distance based on ITS was generally not more than $1.5 \%$, and the genetic distance of some interspecific species was less than $1 \%$. Minimal genetic difference was found among the populations of M. iridescens. Many other molecular markers (e.g. RAPD, SSR, ISSR, AFLP, and etc.) should be used for an in-depth analysis of genetic differences among populations. Genetic diversity is an important indicator used to assess species resources status and is the genetic basis for species to adapt to different environments and maintain long-term survival and evolution (Peng et al., 2012). This study showed that the genetic diversity of the five populations was high which indicated that the germplasm resources were in a good level. Such is the case in other shellfish populations, such as Donax vittatus(Fernandez-Perez, et al., 2017), Mytilus coruscus (Liu et al., 2019), and Perna viridis (Lau et al., 2018). The genetic diversity level is correlated with the effective population size; that is, the larger the effective population size, the greater the genetic contribution of the parents and the greater the selective response will be. Furthermore, genetic drift and the gradual disappearance of genetic variation are less likely to occur (Zhao et al., 2015). The genetic diversity of $M$. iridescens was high due to its high population density. The high level of genetic diversity and the low level of nucleotide diversity could be attributed to the population expansion created by the low effective population. The rapid population growth enhances the retention of neomorphs, resulting in a high level of population genetic polymorphism (Grant et al., 1998).

AMOVA showed that the genetic variation of $M$. iridescens mainly existed within populations $(101.9 \%)$, indicating that the gene exchange is frequent among the population, and no evident genetic differentiation was found. This phenomenon has also been reported in a previous work on Crassostrea rivularis (Yang et al., 2009). The genetic differentiation level of Perna viridis in the South China Sea (Zhangzhou, Zhuhai, Zhanjiang, Beihai), Malaysia, Gulf of Thailand, and Singapore was reported to be relatively low (Ye et al., 2016). Among them, the low genetic differentiation level of $P$. viridis in the South China Sea could be due to its relatively long growing period of planktonic larvae and the type of the marine environment during incubation. Although $P$. viridis lives by attaching itself to the hard bottom, its planktonic larval period is between 21 to 28 days, which provides sufficient opportunities for larval dispersal and enhanced genetic exchange.

The summertime northeastward ocean current over the South China Sea may also be the driving force for gene exchange among sea areas. The rainbow clam spawns in batches with two spawning peaks in one year occurring between late June and late August (You et al., 1990). In July, the average salinity of Yuantuojiao in the north branch ranges from 4.17 to 13.59 , and the average vertical salinity of the South Passage in the south branch ranges between 0.68 and 2.48 at the Yangtze Estuary (Kong et al., 2004). M. iridescens belongs to the euryhaline species, which exist in an environment with suitable salinity of 6.49-26.2, when salinity is lower than 3.87 or higher than 38.6 , euryhaline species do not survive over three days. During the reproductive period, the seawater salinity of Yangtze River Estuary was below 3.87 was found (Kong et al., 2004), which probably caused the death of planktonic larvae and prevented them from expanding into other sea areas. The planktonic larvae period of rainbow clam is relatively short at 9-17 days (You et al., 1990; Wang et al., 1992). The directions of ocean and coastal currents in the Yangtze Estuary are from southwest to northeast in summer (Huang et al., 2016). Thus, the spread of larvae from the reverse coastal current of the north branch to the south is difficult. In addition, the larvae must pass through the low salinity area, which blocks the larvae from 
spreading to the sea area of Zhejiang Province and leads to very rare gene exchange between the CM population and other populations (CX, ZS, ND). In the long term, genetic differentiation should occur between the Yellow Sea and the East China Sea populations.

However, the experimental results showed no genetic differentiation among populations in these two sea areas, probably because of the genetic exchange was diffused artificially. ISSR analysis of Lianyungang, Cixi, and Zhapu populations also showed a low level of population genetic structure with a considerable frequency of gene flow, similar to the results of the present study (Dong et al., 2010). The large effective population without bottlenecks was probably a factor for low genetic differentiation. Each population could maintain the balance of the ancestral population gene to ensure the stability of the population gene pool, leading to the relative stability of genetic diversity. The genetic variation at the population level was studied in detail by ITS, with certain limitations for analyzing shellfish population variation at the molecular scale. Despite the high level of genetic diversity of $M$. iridescens, other species in these areas are at a decline in genetic diversity.

Therefore, the protection of genetic resources in M. iridescens must draw attention. We conclude that it is possible to manage the five populations as a whole population in china based only on the rDNA molecular marker.

\section{Acknowledgments}

This study was supported by grants from the National Natural Science Foundation of China (31101900), Modern Agro-industry Technology Research System (CARS-49), and the Natural Science Foundation of the Jiangsu Higher Education Institutions of China (No. 18KJA240001).

\section{References}

Cheng, H.L., Xia, D.Q., Wu, T.T., Meng., X.P., Ji, H.J., and Dong, Z.G., 2006. Study on sequences of ribosomal dna internal transcribed spacers of clams belonging to the veneridae family (mollusca: bivalvia). Acta Genetica Sinica, 33(8): 702-710. DOI: 10.1016/S0379-4172(06)60102-9.

Dong, Z.G., Li, X.Y., Wang, M.Z., Chen, H.C., Meng, X.P., Cheng, H.L., and Yan, B.L., 2012. Accumulation and cluster znalysis of heavy metals in Moerella iridescens from Hangzhou Bay and Haizhou Bay. Food Science, 33(10): 161-164. (In Chinese)

Dong, Z.G., Li, X.Y., Wang, M.Z., Chen, H.C., Meng, X.P., Cheng, H.L., Yan, B.L., and Li, J.L., 2010. Genetic variation in geographical populations of clam Moerella iridescens from Hangzhou Bay and Haizhou Bay based on ISSR technique. Fisheries Science, 29(8): 460-464. DOI: 10.16378/j.cnki.1003-1111.2010.08.005.

Dyomin, A., Volodkina, V., Koshel, E., Galkina, S., Saifitdinova, A. and Gaginskaya, E., 2017. Evolution of ribosomal internal transcribed spacers in Deuterostomia. Molecular Phylogenetics and Evolution, (116): 87-96. DOI: 10.1016/j.ympev.2017.08.015.

Excoffier, L., Laval, G., and Schneider S., 2005. Arlequin (version 3.0): An integrated software package for population genetics data analysis, Evolutionary bioinformatics online, 1: 47-50. http://cmpg.unibe.ch/software/arlequin3.

Fernandez-Perez, J., Froufe, E., Nanton, A., Gaspar, M.B., and Mendez, J., 2017. Genetic diversity and population genetic analysis of Donax vittatus (Mollusca: Bivalvia) and phylogeny of the genus with mitochondrial and nuclear markers. Estuarine, Coastal and Shelf Science, (197): 126-137. DOI:10.1016/j.ecss.2017.08.032.

Fernández-Tajes, J., Freire, R., and Méndez, J., 2010. A simple one-step PCR method for the identification between European and American razor clams species. Food Chemistry, 118(4): 995-998. DOI:10.1016/j.foodchem.2008.10.043.

Freeland J.R., 2005. Molecular ecology. Chichester: John Wiley \& Sons: 112-116. (Material)

Grant, W.S., and Bowen, B.W., 1998. Shallow population histories in deep evolutionary lineages of marine fishes: Insights from sardines and anchovies and lessons for conservation. Journal of Heredity, 89(5): 415-426. DOI:10.1093/jhered/89.5.415. 
Guo, Z.S., Han L., Liang, Z.L., and Hou, X.G., 2019. Comparative analysis of the ribosomal DNA repeat unit (rDNA) of Perna viridis (Linnaeus, 1758) and Perna canaliculus (Gmelin, 1791). PeerJ, 7(1): e7644. DOI: 10.7717/peerj.7644.

Hu, A.K., and Xue, X.H., 2013. Techniques of Moerella iridesens culture in tide area. Agriculture and Technology. 33(2): 235-236. DOI: 10.3969/j.issn.1671962X.2013.02.185.

Huang, X.W., 2016. The impacts of coastal defense structures on rocky intertidal community in Yangtze River Delta. Xiamen University, Xiamen: 2016. (In Chinese)

Hurtado, N.S., Pérez-García, C., Morán, P., and Pasantes, J.J., 2011. Genetic and cytological evidence of hybridization between native Ruditapes decussatus and introduced Ruditapes philippinarum (Mollusca, Bivalvia, Veneridae) in NW Spain. Aquaculture, (311): 123-128. DOI: $10.1016 /$ j.aquaculture.2010.12.015.

Hwang, J.Y., Lee, C.-K., Kim T.H., Nam B.-H., An, C.M., Park, J.Y., Park, K.-H., Huh, C.S., and Kim, E.B., 2015. Comparative genomic analysis of mitochondrial protein-coding genes in Veneroida clams: Analysis of superfamily-specific genomic and evolutionary features. Marine Genomics, (24): 329-334. DOI:10.1016/j.margen.2015.08.004.

Ji, Y.B., Li, T.W., and Su, X.R., 2007. The biological characteristics of clam Moerella iridescens inshore in Zhejiang Province[J]. Fisheries Science, 26(9): 494-496. DOI: 10.16378/j.cnki.1003-1111.2007.09.009.

Kong, Y.Z., He, S.L., Ding, P.X., and Hu, K.L., 2004. Characteristics of temporal and spatial variation of salinity and their indicating significance in the Changjiang Estuary. Acta Oceanologica Sinica, 26(4): 9-18. DOI: 10.3321/j.issn:0253-4193.2004.04.002.

Lau, J.-S., Ransangan, J., and Rodrigue, K.F., 2018. Genetic diversity and population structure of the Asian green mussel (Perna viridis) in the waters of Sabah, Malaysia based on mitochondrial DNA D-Loop sequences. Turkish Journal of Fisheries and Aquatic Sciences, 18(1): 109-117. DOI: 10.4194/1303-2712-v18_1_12.

Li, B.Q., Li, X.J., Bouma, T.J., Soissons, L.M., Cozzoli, F., Wang, Q.C., Zhou, Z.Q., and Chen, L.L., 2017. Analysis of macrobenthic assemblages and ecological health of Yellow River Delta, China, using AMBI and M-AMBI assessment method. Marine Pollution Bulletin, 119(2): 23-32. DOI: 10.1016/j.marpolbul.2017.03.044.

Li, T.W., Ji, Y.B., and Su, X.R., 2007. Multivariation analysis of nutritive material of Moerella iridescens along the Zhejiang Coast. Journal of Fisheries of China, 31(s1): 88-91. (In Chinese)

Li, X.Y., Dong, Z.G., Wang, M.Z., Chen, H.C., Meng, X.P., Cheng, H.L., Yan, B.L., and Li, J.L., 2010a. Morphological variation in geographical populations of clam Moerella iridescens from Hangzhou Bay and Haizhou Bay. Fisheries Science, 29(11): 648-652. DOI: $10.16378 /$ j.cnki.1003-1111.2010.11.008.

Li, X.Y., Dong, Z.G., Wang, M.Z., Jin, W., Zhao, J.X., Yan, B.L., Chen, H.L., and Li, J.L., 2009. Study on the tissue specificity of isozymes in Moerella iridescens. Marine Sciences, 33(1): 43-47. DOI:10.1007/978-1-4020-9623-5_5.

Li, X.Y., Dong, Z.G., Yan, B.L., Cheng, H.L., Meng, X.P., Li, J.L., and Shen, H.D., 2010b. The transferability of Microsatellite Markers of Clams from GenBank in Cyclina sinensis and Moerella iridescens, First International Conference on Cellular, Molecular Biology, Biophysics and Bioengineering (CMBB 2010), Volume VII. IEEE: 149-152. (Conference)

Li X.Y., Dong Z.G., Wang, M.Z. , Zhao, M.M, Chang, Y.M., and Chen, H.C., 2013. Development and characterization of microsatellite markers for genetic analysis of Moerella iridescens. Conservation Genetics Resources, 5: 59-61. DOI: 10.1007/s12686-012-97333.

Lin, Z.H., Huang, X.T., Dong, Y.H., Bao, Z.M., and Hu, J.J., 2009. Analysis of Meretrix Clams from Guangxi Based on fAFLP Markers and its Sequences. Oceanologia et Limnologia Sinica, 40(1): 33-41. DOI: 10.1016/j.elecom.2008.10.019.

Liu, S.B., Tang, Z.R., Shen, W., Ye, Y.Y., Chen, X.L., Qi, P.Z., and Guo, B.Y., 2019. Study on the genetic diversity of Mytilus coruscus in the east China sea[J]. Oceanologia et Limnologia Sinica, 50(2): 355-364. DOI: 10.11693/hyhz20180900231. 
Meng, X.P., Gao, R.C., Shen, X., Wang, S., Cheng, H.L., Dong, Z.G., and Yan, B.L., 2010. ITS1 sequences variation and phylogenetic analysis on five geographical stocks of Coelomactra antiquata. Acta Ecologica Sinica, 30(20): 5555-5561. DOI:10.1046/j.13652443.1998.00217.x.

Pan, B.P., Wu, Q., Zhang, S.P., Song, L.S., and Bu, W.J., 2006. Molecular phylogeny of Meretrix (Mollusca, Bivalvia) based on 16S rRNA genes and ITS1 sequences. Oceanologia et Limnologia Sinica, 37(4): 342-347. (In Chinese)

Peng, M., Chen, X.L., Jiang, W.M., Yang, C.L., and Li, Y.M., 2012. The population genetic diversity of different geographical Pteria penguin revealed by fAFLP analysis. Acta Hydrobiologica Sinica, 36(1): 102-108. DOI: 10.1007/s11783-011-0280-z.

Qiu, F., Su, Y.Q., Fu, M.N., and Wang, J., 2010. Molecular phylogenetic analysis in Scombridae based on Cyt b and ITS1 fragment sequences. Journal of Fishery Sciences of China, 17(2): 201-211. DOI: 10.3724/SP.J.1011.2010.01351.

Salvia, D., and Mariottini, P., 2012. Molecular phylogenetics in 2D: ITS2 rRNA evolution and sequence-structure barcode from Veneridae to Bivalvia. Molecular Phylogenetics and Evolution, (65): 792-798. DOI:10.1016/j.ympev.2012.07.017.

Si, L.Z., Shi, W., Yang, M., Gong, L., and Kong, X.Y., 2016. Feature analysis of the internal transcribed spacers in teleost ribosomal DNA. Journal of Tropical Oceanography, 35(6):74-81. DOI: $10.11978 / 2016012$.

Sokal, R.R., Jacquez, G.M., and Wooten, M.C., 1989. Spatial autocorrelation analysis of migration and selection. Genetics, 121(4): 845-855. DOI: 10.1101/gad.3.4.572.

Su, T.F., Huang, J.H., Wu, J.F., and Jiang, S.G., 2007. Genetic polymorphism of mitochondrial DNA sequences in Babylonia areolata and Babylonia formosae. Journal of Fishery Sciences of China, 14(3): 369-376. DOI: 10.3321/j.issn:1005-8737.2007.03.004. Tran, T.N., Niu, D.H., Nguyen, H.-D., Xie, S.M., and Li, J.L., 2015. Populations genetic structure of the razor clam Sinonovacula constricta from China, Korea and Vietnam. Biochemical Systematics and Ecology, (61): 429-436. DOI:10.1016/j.bse.2015.07.020.

Tajima, F., 1989. The effect of change in population size on DNA polymorphism, Genetics, 123: 597-601. DOI: 10.1101/gad.3.11.1801.

Wang, Y.N., You, Z.J., Zhang, J.L., and Zhu, X.D., 1992. A preliminary study on the artificial rearing density of larval Moerella iridescens (benson). Journal of Zhejiang Ocean University, 11(2): 110-115. (In Chinese)

Wood, A.R., Apte, S., MacAvoy, E.S., and Gardner, J.P.A., 2007. A molecular phylogeny of the marine mussel genus Perna (Bivalvia: Mytilidae) based on nuclear (ITS1and2) and mitochondrial (COI) DNA sequences. Molecular Phylogenetics and Evolution, 44(2): 685-698. DOI:10.1016/j.ympev.2006.12.019.

Yang, Y.X., Wang, Q.H., Du, X.D., and Shi, S.L., 2009. Genetic diversity of two wild populations of Oyster Crassostrea rivularis. Journal of Guangdong Ocean University, 29(6):16-22. (In Chinese)

Ye, Y.Y., Senanan, W., Li, J.J., Cai, H.W., and Wu, C.W., 2016. Genetic diversity and population structure of the Asian green mussel Perna viridis in South China Sea based on microsatellite markers. Biochemical Systematics and Ecology, 68: 135-141. DOI:10.1016/j.bse.2016.07.010.

You, Z.J., and Wang, Y.N., 1991. A prelimitary study on the artificial seedling rearing of Moerelia iridescens. Transactions of oceanology and limnology, (3): 57-63. (In Chinese)

You, Z.J., Wang, Y.N., Zhu, X.D., Li, R.W., and Ding, L.F., 1990. Preliminary study on population composition and growth of clam Moerella iridescens (Benson). Marine Science Bulletin, 9(6): 35-40. (In Chinese)

Yu, D.H., and Zhu, J.H., 2005a. Phylogenetics of the common pearl oysters in the genus Pinctada: evidence from neclear rDNA ITS sequence. Biodiversity science, 13(4): 315-323. DOI: $10.1360 /$ biodiv. 050050.

Yu, D.H., and Zhu, J.H., 2005b. Study on ITS 2 molecular markers of six pearl oyster species in the genus Pinctada. South China Fisheries Science, 1(4): 6-17. (In Chinese)

Yu, D.H., and Zhu, J.H., 2006. Species status of Chinese Pinctada fucata, Japanese P.fucata martensii and Australian P.imbricata using ITS and AFLP markers. South China Fisheries Science, 2(1): 36-44. (In Chinese) 
Yu, H., Xue, L.Y., and Zhang, J.F., 2009. Genomic DNA isolation and RAPD analysis on Moerella iridescens. Marine Sciences, 33(3): 4-9. DOI: 10.1016/j.elecom.2008.10.019.

Yuan, Y., Gao, W.W., Wu, Q., and Pan, B.P., 2008. Genetic variation and structure of Cyclina Sinensis populations in the Yellow and Bohai Sea of China. Oceanologia et Limnologia Sinica, 39(6): 665-670. DOI: 10.3724/SP.J.1141.2008.00373.

Zhao, L.Q., Liang, J., Yan, X.W., Huo, Z.M., and Yang, F., 2015. Effects of effective population size on the F1 growth and survival of the Manila clam Ruditapes philippinarum. Marine Sciences, 39(1): 64-69. DOI: 10.11759/hykx20120927002.

Zhou, A.G., Xie, S.L., Chen, J.T., Chen, Y.F., and Zhou, J.X., 2015. Molecular phylogenetic relationships of five species of Epinephelus based on sequences of rDNA ITS1. Marine Sciences, 2015, 39(8): 7-15. DOI: 10.11759/hykx20131126002.

Zhou, L.Q., Yang, A.G., Wang, Q.Y., Wu, B., and Yu, T., 2012. ITS sequence variation and phylogenetic analysis on four geographical populations of blood clam Scapharca broughtonii. Progress in Fishery Sciences, 33(5): 78-84. (In Chinese) 